during the past twenty years, and the jury returned a verdict of " Death from Misadventure."

\title{
CRIMINAL ANTHROPOLOGY.
}

The Italian Chamber of Deputies have passed the second reading of the Government Bill relating to habitual criminals. High praise was given to the late $\mathrm{Dr}$. Bruce Thomson in the course of the debate. The present penal system was unsparingly denounced, and large hopes of social improvement were held out consequent on the operation of the new law. The incidents and observations of the last three years, together with this action on the part of Italy, will afford material for discussion at the International Congress of Criminal Anthropology which is to be held at the Hague in August next.

\section{CRIMINAL LUNATICS IN ORDINARY ASYLUMS.}

Lord Sandwich, at a meeting of the Huntingdonshire County Council, lately referred to the case of a man named Clifton, who had been tried for attempted murder, but was ordered to be detained during Her Majesty's pleasure. Clifton would have been sent to Broadmoor, but it was full, and the only alternative was to send him to the Three Counties Asylum. There was no reason to consider him dangerous, but only of weak intellect. Clifton managed to get amongst the stream of patients going out at one door when he should have gone out at another. He had never since been heard of. It was impossible to prevent a recurrence of this, because the whole principle of the care of lunatics was that they should be subjected to as little restraint as was possible. A caution had, however, been given to the attendants that a more careful watch should be set on those who were suspected of homicidal mania, or were dangerous to themselves or others. Beyond that it was impossible to go, except by such an increase of staff as would necessitate a total reorganisation and a reconstruction of the asylums throughout the country. If pressure was put on the Government, and they could see their way to provide more accommodation for criminal lunatics of this character, it would be the best way to prevent such escapes. Lord Sandwich moved that the attention of the Home Secretary be called to the matter, and this course was agreed to.

We trust that this case will cause some decided action on the part of the Government, for it has long been evident that such patients are unsuitable for ordinary treatment, and detrimental to the interests of their fellows in county asylums.

\section{LUNACY IN COUNTRY DISTRICTS.}

Dr. Bowes has issued a most interesting report on the existing high rate of lunacy in Wiltshire.

The first question discussed is whether the apparent increase of insanity in England is real or only due to accumulation of the chronic insane and the removal of many quiet dements from their homes and asylums. Dr. Bowes agrees with the general impression that there is some increase, but not enough to create alarm. He points out that there is a much larger proportion of insane to sane among the agricultural labourers than among miners and city dwellers. He shows that for thirty years the agricultural counties have shown most pauperism and most insanity. He thinks that marrying in and the poorness of the living and generally depressing vital conditions account for this. All this is true, but we believe that it is true also that the more feeble are left in the country to breed degenerates and to live from hand to mouth. The morally weak as well as the mentally feeble tend to collect 